\title{
CHRONIC GROIN PAIN FOLLOWING LICHTENSTEIN MESH HERNIOPLASTY FOR INGUINAL HERNIA
}

\author{
Ajay Saha ${ }^{1}$, Prabir Kr. Saha ${ }^{2}$ \\ ${ }^{1}$ Associate Professor, Department of Surgery, Tripura Medical College. \\ ${ }^{2}$ Associate Professor, Department of ENT, Tripura Medical College.
}

\begin{abstract}
AIMS AND OBJECTIVES

To assess the incidence of Chronic Groin pain following Lichtenstein Mesh Hernioplasty for Inguinal Hernia.

\section{MATERIALS AND METHODS}

The study includes 210 patients from December 2010-November 2014 who underwent Lichtenstein Mesh Hernioplasty for Inguinal Hernia, but only 154 patients reported at three months and 147 reported at six months. Because 63 patients did not report at six months, they were finally excluded from the study. So ultimately 147 patients were considered in the study.

\section{RESULT}

Of the 147 patients who were finally included in the study 135 were unilateral and remaining 12 were bilateral hernia. Most of the patients were in the age group of 50-60 years. Right sided inguinal hernias were much more common. All the patients were male. The CGP were complained by 2 patients at six months. One patient had mild and the other one had pain of moderate severity.

\section{CONCLUSION}

This study shows that CGP does really exist. But the magnitude of the problem is not as vast as suggested by the other studies. So procedure like deliberate sacrifice of nerves is difficult to justify at present. Though laparoscopic hernia repair may be an alternative in which CGP is even less, but laparoscopic repair is time consuming, has a steep learning curve and requires expensive instruments which is currently not available in many hospitals.
\end{abstract}

\section{KEYWORDS}

Lichtenstein Mesh Hernioplasty (LMH), Hernioplasty.

HOW TO CITE THIS ARTICLE: Saha A, Kr. Saha P. "Chronic groin pain following Lichtenstein mesh hernioplasty for inguinal hernia." Journal of Evolution of Medical and Dental Sciences 2015; Vol. 4, Issue 103, December 24; Page:16899-16900,

DOI: $10.14260 /$ jemds/2015/2542

\section{INTRODUCTION}

Hernia repair dates back to the era of Egyptian Pharaohs of ancient time (BC). Inguinal hernia repair is a very common surgical procedure, of which Lichtenstein Mesh Hernioplasty (LMH) is a very popular procedure amongst surgeons due to its negligible recurrence rate. ${ }^{[1,2]}$ This tremendous advantage has partly been offset by reported prevalence of Chronic Groin Pain (CGP). ${ }^{[3,4]}$ CGP may cause significant delay in resuming normal activities and return to work. The present study was undertaken to assess the incidence of CGP following LMH.

\section{METHODS}

Chronic pain is defined as pain present at the site of operation even after three months of surgery. [5] Three months period is required for normal tissue healing and also fulfils the criteria of definition of chronic pain. CGP is defined as posthernioplasty pain that continues to hamper the lifestyle of patient more than three months following surgery. CGP is a significant morbidity.

Present study tried to ascertain the prevalence of CGP following LMH. In this study includes 210 patients from December 2010 - November 2014. But only 154 patients reported at three months and 147 reported at six months.

Financial or Other, Competing Interest: None.

Submission 05-12-2015, Peer Review 06-12-2015,

Acceptance 19-12-2015, Published 24-12-2015.

Corresponding Author:

Dr. Ajay Saha,

Associate Professor,

Department of Surgery,

Tripura Medical College,

Hapania, Agartala-14.

E-mail: drajaysaha@yahoo.in

DOI:10.14260/jemds/2015/2542
Because 63 patients did not report at six months, they were finally excluded from the study. So ultimately 147 patients were considered in the study.

All the patients were adult above the age of 17 . In case of bilateral hernias, operations were done in the same siting.

All the operations were carried out under spinal anesthesia with skin incision $2 \mathrm{~cm}$ above the medial $3 / 5$ th of the inguinal ligament. During the procedure, all the nerves were identified and safe guarded. No deliberate division of nerves were done. Direct sacs were inverted and for indirect sac herniotomy were done. Using a proper sized polypropylene mesh, which extended $2 \mathrm{~cm}$ medial to pubic tubercle, $3 \mathrm{~cm}$ above the Hesselbach's triangle and $5 \mathrm{~cm}$ lateral to the inguinal ring, LMH were done; $2-0$ vicryl were used to fix the mesh in the conjoint above and rectus sheath medially. Fixation of the lower edge of the mesh with inguinal ligament were done with continuous suture using 3-0 polypropylene. After discharge from hospital all the patients were followed up at OPD at three months and six months. Pain was recorded as mild, moderate and severe.

\section{RESULT}

Of the 147 patients who were finally included in the study, 135 were unilateral and remaining 12 were bilateral hernia. Most of the patients were in the age group of 50-60 years. Right sided inguinal hernia were much more common. All the patients were male. During the followup, there was no recurrence. The CGP were complained by 2 patients at six months. One patient had mild and the other one had pain of moderate severity.

\section{DISCUSSION}

Cunningham et al.[6] were first to raise the issue of CGP. Thereafter, it has been reported by many. This study intended 
to explore the prevalence of CGP amongst the post LMH patients in the local population.

CGP is an important measure of postoperative outcome whose incidence reportedly as high as 63\%.[7,8] CGP may be acute or chronic. CGP may be due to somatic (Nociceptive), neuropathic and visceral somatic is the commonest type of CGP, which is due to local trauma and inflammation. This may be reproduced by contraction of abdominal wall muscles, which responds to rest and NSAIDs. Neuropathic pain occur from nerve entrapment or its damage and may respond to pharmacotherapy. Visceral pain is poorly localized and may occur during ejaculation, as a result of sympathetic plexus injury.

Meticulous identification of nerves may prevent CGP, which is possible as shown in this study. Identification and safe guarding of the ilioinguinal and iliohypogastric nerves are important, so that these two nerves neither get injured nor entrapped. Nerve entrapment give rise to acute neuropathic pain that is distributed along a dermatome. Genitofemoral nerve injury occurs during isolation of the spermatic cord and dissection of cremaster muscle.

After identification of iliohypogastric, ilioinguinal and genitofemoral nerves, they should be kept out of the operative field and also avoided excessive retraction. Another cause for CGP is osteitis pubis caused by inflammation of symphysis pubis. In osteitis pubis, CGP can be reproduced by adduction of thigh and is prevented by avoiding picking up periosteum, which was never done in this study. Another important factor is tissue respect by gentle handling. Avoiding rough handling of tissue intraoperatively help prevention of nociceptive pain. The one patient who suffered from moderately severe type of CGP, might have suffered nerve injury in spite of all possible precaution and this is supported by the fact that it was accompanied by sensory symptoms. The other patient who suffered mild CGP may be due to muscular or ligamentous injury akin to that observed in athletes.

\section{CONCLUSION}

This study shows that CGP does really exist. But the magnitude of the problem is not as vast as suggested by the other studies. So procedure like deliberate sacrifice of nerves is difficult to justify at present. Though as suggested in literature.[5] laparoscopic hernia repair may be an alternative, in which CGP is even less but laparoscopic repair is time consuming, has a steep learning curve and requires expensive instruments which is currently not available in many hospitals.

\section{REFERENCES}

1. The EU Hernia Trialists Collaboration 2002. Repair of groin hernia with synthetic mesh. Meta-analysis of randomized control trials. Ann Surg 235:322-332.

2. Holzheimer RG (2007). Low recurrence rate in hernia repair- Results in 300 patients with open mesh repair of primary inguinal hernia. Eur J Med Res 12(1):1-5.

3. Loos MJ, et al. 2007. Chronic sequelae of common elective groin hernia repair. Hernia 11:169-173.

4. Page B, et al. (2002). Pain from primary inguinal hernia and the effects of repair on pain. Br J Surg 89:1315-1318.

5. Norman S Williams, et al. Bailey and Love's Short Practice of Surgery, 26 $6^{\text {th }}$ edn, 2013 by Taylor and Francis Group, Boca Raton abdominal wall hernia and umbilicus. 60:949-969.

6. Cunningham J, et al. Cooperative hernia study. Pain in the post hernia repair patient. Ann Surg 1996;224:598-602.

7. Kehlet H. Chronic pain after groin hernia repair. Br J Surg 2008;95:135-136.

8. Alfieri $\mathrm{S}$, et al. International guidelines for prevention and management of post-operative chronic pain following inguinal hernia surgery. Hernia 2011;15:239249. 